3 Sandrine A. Zweifel, MD, ${ }^{1}$ Daniela Mihic-Probst, $\mathrm{MD},{ }^{2}$ Christine A. Curcio, $\mathrm{PhD},{ }^{3}$ Daniel Barthelmes, $\mathrm{MD}$ PhD, ${ }^{1,4}$ Andrea Thielken,

$4 \quad \mathrm{MD},{ }^{2}$ Peter M. Keller, MD ${ }^{5,6}$, Barbara Hasse, $\mathrm{MD}^{7 *}$, Christian Böni, MD ${ }^{1 *}$

$6 \quad$ Running title: Ocular findings associated with $M$. chimaera infection

$8{ }^{1}$ Department of Ophthalmology, University Hospital Zurich, University of Zurich, Frauenklinikstrasse 24, 8091 Zurich, Switzerland.

$9 \quad{ }^{2}$ Institute of Pathology, University Hospital Zurich, University of Zurich, Schmelzbergstrasse 12, 8091 Zurich, Switzerland.

$10{ }^{3}$ University of Alabama School of Medicine, Department of Ophthalmology, Birmingham, Alabama, USA.

$11{ }^{4}$ The Save Sight Institute, The University of Sydney, Sydney, Australia

125 Institute of Medical Microbiology, University of Zurich, Gloriastrasse 30/32, 8006 Zurich, Switzerland

$13{ }^{6}$ Swiss National Center for Mycobacteria, University of Zurich, Institute of Medical Microbiology, Gloriastrasse 30/32, 8006 Zurich,

14 Switzerland 
$1{ }^{7}$ Division of Infectious Diseases and Hospital Epidemiology, University Hospital Zurich, University of Zurich, Raemistrasse 100,

28091 Zurich, Switzerland

$3 \quad$ *These authors contributed equally to this work (shared senior author)

4 Corresponding Author:

5 Sandrine A. Zweifel, MD Frauenklinikstrasse 24, 8091 Zurich, Switzerland

$6 \quad$ e-mail: sandrine.zweifel@usz.ch

$7 \quad$ Phone: +41 4425587 94; Fax: +41 442554472

8 Conflicts of interest: None of the authors has any conflicts of interests. 
1 Key Words: Spectral domain optical coherence tomography, non-tuberculous mycobacterial (NTM) infection, fundus autofluorescence, Mycobacterium chimaera, multifocal choroiditis, choroidal tubercles, granulomatous choroiditis, Mycobacterium

3 avium complex (MAC), cardiac surgery.

4

5 Précis:

6 Systemic infection with $M$. chimaera may result in severe retinal and choroidal abnormalities.

7 Ocular manifestations represent an easily accessible window on the systemic control of the disease and could be useful in

8 diagnosing/predicting cases refractory to therapy. 
1 Abstract:

2 Purpose: To investigate and characterize clinical and histopathologic ocular findings in patients with disseminated infection with

3 Mycobacterium chimaera, a slowly growing non-tuberculous mycobacterium (NTM), subsequent to cardiothoracic surgery.

4 Design: Observational case series.

$5 \quad$ Participants: Five Caucasian patients (10 eyes).

6 Methods: Analysis of clinical ocular findings including visual acuity, slit-lamp biomicroscopy, spectral domain optical coherence

7 tomography (SD-OCT), fundus autofluorescence (FAF) and fluorescein (FA)/ indocyanine green (ICG) angiography findings of

8 patients with a disseminated $M$. chimaera infection. Biomicroscopic and multimodal imaging findings were compared with

9 histopathology of one patient.

10 Main Outcome Measures: Clinical and histopathologic ocular findings of M. chimaera.

11 Results: The mean age of the five male patients, diagnosed with either endocarditis and/or aortic graft infection, was 57.8 years.

12 Clinical ocular findings included anterior and intermediate uveitis, optic disc swelling and white-yellowish choroidal lesions.

13 Multifocal choroidal lesions were observed bilaterally in all patients and were hyperfluorescent in FA, hypofluorescent in ICG and

14 correlated with choroidal lesions in the SD-OCT. The extent of choroidal lesions varied from few in two patients to widespread

15 miliary lesions in three patients leading to localized choroidal thickening with elevation of the overlying retinal layers. SD-OCT

16 imaging through regressing lesions revealed altered outer retinal layers and choroidal hypertransmission. The ocular findings were 

with widespread chorioretinitis died due to systemic complications of M. chimaera infection despite long-term targeted antimicrobial

3 therapy. Ocular tissue was obtained from one patient at autopsy. Necropsy of two eyes of one patient revealed prominent granulomatous lymphohistiocytic choroiditis with giant cells.

5 Conclusions: $M$. chimaera infection subsequent to cardiothoracic surgery is a novel entity that has been recently described. It involves 6 multiple organ systems and can cause life-threatening disseminated disease. The ocular manifestations documented using multimodal 7 imaging allow us to use the eye as a window to the systemic infection. 
2 (MAC)(1) M. chimaera was identified as a species within the MAC complex in 2004. NTM have been recovered from drinking water

3 in patients' households and other environmental sources including soil, food, dust, aerosols and animals. $(2,3)$ M. chimaera infections

4 usually cause respiratory infections and disseminated infections among immunocompromised patients. Recently, outbreaks of

5 M. chimaera infections were reported among patients who underwent cardiovascular surgery in Switzerland (4, 5), in other European

6 countries $(6,7)$, and in the US (8). Many of these cases were linked to airborne contamination of heater-cooler units (HCU) used

7 during extracorporeal circulation $(9,10)$. M. chimaera has been implicated in prosthetic heart valve, prosthetic aortic graft, and

8 disseminated infections among heart surgery patients $(4,5)$. Prior to this outbreak mycobacterial cultures have not been part of the

9 routine microbiological work-up in the case of cardiovascular infections. Based on international experience (prevalence 2 cases per

10 mil), we estimate that additional cases may continue to be identified over the coming years, given the long incubation period.

11 Currently, there are no guidelines for the treatment of serious M. chimaera infections. Surgical excision of the infected cardiovascular

12 device together with a combination of antimicrobial agents directed against $M$. chimaera is recommended, depending on susceptibility

13 testing (5).

14 These infections seem to have a preference for an ocular involvement (5). We present five cases of bilateral chorioretinitis associated

15 with disseminated $M$. chimaera infections that were acquired during cardiopulmonary bypass surgery. We used multimodal

16 chorioretinal imaging and histopathology for patient work-up. 


\section{Patients, Material and Methods}

\section{Case detection}

4 As of February 2015, a total of six patients with $M$. chimaera infection who had undergone cardiothoracic surgery at the Zurich Heart

5 Center were identified. Methods of case identification have been described elsewhere $(4,9)$. Based on a thorough histopathologic

6 analysis of cardiac tissue in the first patient, M. chimaera could be identified by polymerase chain reaction (PCR) (4). In the

7 subsequent patients diagnosis was based on either positive mycobacterial tissue cultures, 16SrRNA PCR, or mycobacterial blood 8 cultures (5).

9 We were able to obtain ophthalmologic findings in 5 out of 6 patients treated at the University Hospital Zurich. One patient (case 1) of

10 this series died prior to ophthalmological examination and is not described herein. We collected ophthalmological information at

11 baseline (diagnosis of systemic $M$. chimaera infection) and during prospective follow-up. In addition, data on the index surgery and

12 data on the treatment course and outcome were collected. Institutional review board approval (Ethics Committee of the University of

13 Zurich, BASEC-Nr. PB_2016-00264) was obtained and all patients gave informed consent to publish their clinical data. 
1 All patients underwent a complete ophthalmological examination including biomicroscopy, color fundus photography including ultra wide-field photography using Optomap scanning laser ophthalmoscope (Optos®, Marlborough, MA, USA), spectral domain optical coherence tomography (SD-OCT) including enhanced depth imaging (EDI) technique, fundus autofluorescence (FAF) imaging and fluorescein/indocyanine green angiography (FA/ICG). The wide-field angiograms were either obtained with the Optomap system or with the ultra-widefield module for the Heidelberg Spectralis ${ }^{\circledR}$ HRA+OCT.(11) The SD-OCT and EDI-OCT images were obtained

6 with the Heidelberg Spectralis (version 1.9.10.0) as viewed with the contained Heidelberg software (Spectralis Viewing Module 7 6.0.9.0; Heidelberg Engineering, Heidelberg, Germany). In the present study at least 31 B-scans were obtained within a $20 x 25^{\circ}$

8 rectangle centered on the macula, with the scan pattern adapted according to the location and size of the lesions. Choroidal imaging

9 was obtained using the same instrument in EDI mode.(12) FAF images were obtained in all patients using the confocal scanning laser

10 ophthalmoscope (Heidelberg Retina Angiograph, HRA2, Heidelberg Engineering; Heidelberg, Germany). In addition, automated

11 static perimetry $\left(60^{\circ}, 169\right.$ stimuli; Octopus, Haag Streit; Köniz, Switzerland) was performed in all patients. The size of the lesions was 12 measured on ICG angiograms.

The presence of any pathologic ocular findings such as keratitis, uveitis, optic disc swelling, and retinal or choroidal abnormalities were recorded. For classification of uveitis, criteria of the Standardization of Uveitis Nomenclature Working Group were applied.(13) Additionally the presence of any fluid using SD-OCT was noted. After diagnosis of ocular involvement, eye examinations were performed at least every 3-4 months. 


\section{Histopathology}

3 An autopsy was performed in one patient who died in the setting of a disseminated $M$. chimaera infection (case 5). A necropsy of his

4 enucleated eyes was performed 41 hours after death. The relatively long death to preservation time is due to the fact that the patient

5 died in another hospital. After fixation in buffered $4 \%$ formalin the right globe was sagittal, the left globe horizontally bisected and

6 placed in a tissue processor. As soon as the tissue had been dehydrated and infiltrated with paraffin, the globes were cut into 2 mm

7 slices prior to paraffin embedding. Two $\mu \mathrm{m}$ thick slides were cut and stained with HE, Brown Brenn, PAS, Grocott, Ziehl Neelsen and

8 Auramin-rhodamine. Additionally, immunohistochemistry was performed using an automated immunostainer (Ventana Medical

9 Systems, Tucson, AZ, USA), utilizing antibodies against T-helper cells (anti-CD4 (Ventana-Roche, clone SP35, dilution 1:10),

10 cytotoxic T-cells (anti-CD8 (DAKO A/S, clone C8/144/B, dilution 1:10), macrophages (anti-CD68 (DAKO A/S, clone PG-M1,

11 dilution 1:50), and granulocytes (anti-MPO (NeoMarkers/ Lab Vision Corporation, dilution 1:200).

\section{Microbiologic investigation}

13 We used the MGIT 960 system (Becton Dickinson Microbiology Systems, Sparks, MD, USA) and Middlebrook 7 H11 agar plates

14 incubated at $37^{\circ} \mathrm{C}$ for seven weeks or until positive. Sequencing for the $16 \mathrm{~S}$ rRNA gene was performed as described before (14). In

15 addition, a Mycobacterium genus-specific PCR was performed.(15)

\section{Results}




\section{Patient characteristics}

2 Five Caucasian patients (10 eyes) aged between 51 and 65 years were examined. All patients were diagnosed with either endocarditis

3 and/or aortic graft infection with $M$. chimaera after a cardiothoracic surgery with extracorporeal circulation performed in Zurich

4 between June 2008 and May 2012. All patients had a negative serology for human immunodeficiency virus. The median duration from

5 cardiac surgery to diagnosis of $M$. chimaera infection was 20 (range 16-42) months. The median duration from cardiac surgery to

6 diagnosis of ocular inflammatory abnormalities was 25 (range 20-63) months. The median follow-up duration after diagnosis of ocular

7 abnormalities was 13 (range 1 to 21 ) months. All intraocular pressure measures were normal at all eye visits with values between 9

$8 \mathrm{~mm} \mathrm{Hg}$ to $19 \mathrm{~mm} \mathrm{Hg}$. As of May 2016, three of these five patients died due to systemic complications, related to uncontrolled $M$.

9 chimaera infection despite prolonged antimicrobial therapy. Antimicrobial therapy consisted of clarithromycin, rifabutin, ethambutol,

10 plus/minus amikacin, or moxifloxacin (Table 1).

11

\section{Clinical ocular findings}

13 Clinical ocular findings included mild anterior and intermediate uveitis, optic disc swelling and white-yellowish choroidal lesions suggestive of chorioretinitis. The extent of the choroidal lesions varied from few choroidal lesions (2-5/eye) in two patients (cases 3

15 and 4, Fig. 1) to progressive and widespread lesions in three patients (cases 2, 5 and 6, Fig. 2-4). A detailed description of the ophthalmologic findings of each patient is given below starting with the two patients with mild ocular abnormalities (case 3 and 4 , 
1 Fig. 1). The case number refers to the order the patients presented to the ophthalmology department and is identical to the previously published case series. Additional information on clinical presentation treatment and outcome of infected patients is shown in Table $\mathbf{1}$.

\section{Case 4 (mild ocular abnormalities, Fig. 1)}

4 In this 49-year-old male patient (case 4) a mechanical aortic valve replacement was performed in 2009. Three and a half years after

5 index surgery he developed prosthetic valve endocarditis. He was re-operated with aortic root replacement and the explanted aortic

6 valve was positive for M. chimaera. At this point, best-corrected visual acuity was 20/20 in both eyes on ophthalmological

7 examination, and visual field and color vision were both normal. The anterior chamber and the vitreous were quiet. A few choroidal

8 lesions (2-5 lesions per eye) were observed in both eyes. (Fig. 1A, 1B, only left eye is displayed). These whitish lesions were small

9 (around $300 \mu \mathrm{m}$ in diameter) with well-defined borders (Fig. 1A, 1B). The lesions became atrophic and were stable during follow-up

10 of 18 months under targeted antimicrobial therapy (clarithromycin, ethambutol, rifabutin, moxifloxacin, amikacin), until they were

11 classified as inactive. The corresponding OCT scans demonstrated atrophic changes in the outer retina and marked atrophy of the

12 choroid as well (Fig. 1C).

\section{Case 3 (mild ocular abnormalities)}

14 Disseminated $M$. chimaera infection in this case of a 65-year-old man was observed 39 months after mitral valve reconstruction. On

15 ophthalmologic examination more than five years after cardiac index surgery, a mild uveitis with $0.5+$ anterior chamber cells and $0.5+$

16 vitreous cells was diagnosed bilaterally. Only a very few and subtle chorioretinal lesions (2-5 lesions per eye) were observed, similar 
to the lesions observed in case 4 (Fig. 1). Visual acuity was normal (20/20). The mitral annuloplasty ring was replaced by a biological prosthesis, and tuberculostatic therapy was administered for over a year after redo surgery. The patient is currently in post treatment follow-up and until now ocular check-ups show inactive atrophic chorioretinal lesions without occurrence of new lesions, 18 months after diagnosis of ocular involvement.

Case 2 (progressive ocular disease, Fig. 2)

In this 51-year-old male patient a composite graft surgery was performed in 2010 due to aortic dissection. Sixteen months later he was hospitalized with a 2-month history of fever of unknown origin and was ultimately diagnosed with disseminated $M$. chimaera infection. M. chimaera was detected by culture from bone marrow, heparin blood, urine and sputum. He was treated with clarithromycin, ethambutol and rifabutin according to standard protocol. (16) Two years after cardiac surgery, he presented to our outpatient ophthalmology clinic with a two-month history of photopsia. Visual acuity (VA) was 20/20 in both eyes. In both eyes, panuveitis was diagnosed including endothelial precipitates, $0.5+$ anterior chamber cells, mild vitreous inflammatory reaction with 0.5+ vitreous cells, a mild optic disc swelling and multifocal chorioretinal lesions in both eyes. Follow-up checks on ocular findings revealed a progressive disease in both eyes despite tuberculostatic therapy. Multiple flat, cream-colored lesions scattered in the posterior pole and the periphery were observed (Figure 2A, 2C, 2E), many of which had indistinct borders (Fig. 2E). Depending on the activity status of the lesion they appeared hyper- (Fig. F) or hypo-autofluorescent (Fig. 2 E). New active lesions that were 
hyperautofluorescent could be observed close to atrophic hypoautofluorescent lesions (Fig. 2B, 2F). Ultimately, the patient died due to splenic rupture and disseminated mycobacterial infection.

3 Case 6 (progressive ocular disease, Fig. 3)

4 In this case of a 63-year-old male a more widespread disease was observed. In 2012 he had undergone an aortic root and arch

5 replacement. Twenty months later a graft infection with $M$. chimaera and Propionibacterium acnes was diagnosed. Two weeks after a

6 graft preserving surgery with extensive debridement of infected peri-aortic tissue and 22 months after index surgery, a first

7 ophthalmologic workup was performed. Best-corrected visual acuity tested was 20/20 in the right and 20/25 in the left eye. In the left

8 eye an anterior uveitis with 1+ cells was diagnosed and was subsequently treated with prednisolone eye drops. The fundus exam

9 revealed multiple yellow-white choroidal lesions in both eyes at the posterior pole and the periphery (Fig. 3A, 3B). Some of the

10 lesions had indistinct borders whereas others seemed to be less active leading to an atrophic scar in the choroid in the course of the

11 disease. The active multifocal choroidal lesions were initially hypofluorescent in the FA (Fig. 3C) with staining in the later frames

12 (Fig. 3D). A swollen optic disc was observed in both eyes. Using ICG, many more lesions could be identified and they appeared

13 hypofluorescent in the early (Fig. 3E) and late frames (Fig. 3F). Eight months later, many new choroidal lesions became apparent. The

14 size of the lesions ranged from $50 \mu \mathrm{m}$ to $1100 \mu \mathrm{m}$. Along with progression of the ophthalmic manifestations a cerebral vasculitis was

15 diagnosed. At this time blood cultures were positive for $M$. chimaera despite being under antimicrobial therapy. The patient declined

16 any further cardiothoracic intervention and died 13 months after documentation of ocular involvement. 


\section{Case 5 (progressive ocular disease, Fig. 4)}

This 61-year-old male (case 5) underwent an aortic root and arch replacement and developed 20 months after open cardiac surgery a composite graft infection together with a spondylodiscitis due to M. chimaera. Quadruple antimicrobial therapy was initiated. At this time point, the eye examination showed full visual acuity (20/20) in both eyes, anterior chamber and vitreous were quiet. The fundus exam revealed multiple yellow-white choroidal lesions in both eyes (20-30 lesions per eye) at the posterior pole and the periphery (Fig. 4A, 4B). The size of the lesions ranged from $50 \mu \mathrm{m}$ to $1100 \mu \mathrm{m}$. Some of the lesions had indistinct borders whereas others seemed to be less active leading to an atrophic scar in the choroid in the course of the disease. Over a 9 months' follow-up, the lesions (Fig. 4A) increased in size (Fig. 4B) and new lesions appeared (Fig. 4B). The corresponding OCT of these whitish lesions demonstrated a localized choroidal thickening with elevation of the overlying retinal layers and irregularities of the outer retina. Not only in the posterior pole but also in the periphery, a progression of the disease could be observed. Using ICG, more lesions could be identified as compared to biomicroscopy alone, and they appeared hypofluorescent representing active choroiditis (Fig. 4E, 4F). The progressive multifocal chorioretinitis led to evaluation and performance of redo surgery. At the time of redo surgery $9 / 10$ microbiological samples were positive for M. chimaera. Despite targeted antimicrobial therapy the patient died 12 month after reliable diagnosis of disseminated M. chimaera infection. Postmortem specimens of eyes, lung, heart, liver, spleen, kidney and brain were obtained.

\section{Histopathologic findings and autopsy of Case 5 (Fig. 5 and 6)}


1 Histopathology of both eyes revealed prominent patchy lymphohistiocytic and granulomatous choroiditis. Granulomas within the choroidal stroma consisted of lymphocytes, of histiocytes with epithelioid cell morphology and of a few Langerhans giant cells.

3 Necrosis was not apparent. Lymphocytes were mostly of the T-helper type with positivity for CD4 (Fig. 6 A-D). The optic nerve demonstrated edema and a few lymphocytic infiltrations (not shown). Brown Brenn, PAS, Grocott,Ziehl Neelsen and Auraminerhodamine staining were negative. The $16 \mathrm{~S}$ rRNA analysis of ocular tissue did not reveal M. chimaera in ocular choroidal tissue. The

6 Mycobacterium genus-specific PCR was negative as well.(17) The lung and the right kidney were positive for acid-fast bacilli. Other autopsied organs with granulomatous inflammation (kidney and brain) were negative for acid-fast bacilli.

\section{Discussion}

These cases show for the first time in literature the spectrum of ocular manifestations of disseminated M. chimaera infections among heart surgery patients presenting with aortic graft infection and/ or prosthetic valve endocarditis.(5) All patients of this series demonstrated either mild or severe bilateral choroidal involvement, with some patients showing a miliary picture as a sign of dissemination of mycobacteria. The extent of choroidal lesions were indicative of the degree of systemic disease control, and the lymphohistiocytic and granulomatous changes of ocular tissue suggested that $M$. chimaera had a direct effect on the choroid. A choroidal involvement of systemic NTM infections is rare (18). Ocular mycobacterial infections published in the literature are mostly caused by rapidly growing mycobacteria, and they are frequently associated with prior ocular surgery and ocular biomaterials 
(18-23). Endogenous endophthalmitis and multifocal choroiditis by slowly growing mycobacteria has only been reported among HIV patients $(18,21,22,24)$.

Posterior uveitis with involvement of the choroid is a common presentation of ocular tuberculosis (25). The clinical appearance of the choroidal lesions observed in our series was similar to multifocal choroiditis observed in ocular tuberculosis (26, 27). The lesions ranged from 50 to $1100 \mu \mathrm{m}$ in diameter, and no lesion exceeded 1 optic disc diameter. Thus, they would be considered as "small" by the current classification systems (28). Using ICG many more lesions could be detected which were not visible by ophthalmoscopy. SD-OCT imaging through lesions in regression (inactive lesions) revealed altered outer retinal layers especially the ellipsoid zone with hypertransmission. The enhanced depth imaging-OCT (EDI-OCT) scans through active lesions demonstrated localized choroidal thickening with elevation of the RPE and associated loss or irregularity of the ellipsoid zone suggestive of an underlying choroidal nodule as recently described for ocular tuberculosis (Fig. 4C,4D) (29). The internal pattern of active granulomas was more homogenous than the surrounding vasculature very similar to choroidal granulomas observed in patients with tuberculosis, sarcoidosis and Vogt-Koyanagi-Syndrome (28). A disc staining was only observed in one patient, and retinal vasculitis or retinal vasculopathy was not detected in any patient. Active lesions, which were hyperautofluorescent using FAF could be observed in close proximity to healed lesions (Figure 2). Increased autofluorescence in acute or sub-acute phases have been described in various inflammatory ocular diseases. Hyperautofluorescence in inflammatory lesions has been suggested to originate from accumulation of 
fluorophores secondary to inflammation in RPE or from reduced screening of RPE due to photoreceptor attenuation $(30,31)$.

2 Hyperautofluorescence observed in these lesions could also be due to RPE dysmorphia (32). scarring (26). On the contrary, NTM infections in and around the eye are clinically recalcitrant requiring a long-term therapy and sometimes eye surgery (24). The choroidal lesions reflected systemic disease activity and the response to antimicrobial therapy. In controlled systemic disease only a few choroidal lesions with no progression in size or number were observed, whereas in progressive disease widespread choroidal lesions with increasing size and number were documented. The reason for the ocular predilection is currently unclear. However, the high blood flow of the choroid could be a contributing factor $(29,33,34)$. Moreover, M. chimaera like M. tuberculosis is an obligate aerobic bacterium, usually found in tissue with high oxygen levels $(26,35)$.

11 Hematogenous M. chimaera infection was confirmed showing the same granulomatous inflammation in the lung, kidney and brain,

12 and viable mycobacteria could be demonstrated in granulomas of the right kidney and the lung. However, the Ziehl Neelsen and the

13 Auramine-rhodamine staining as well as mycobacterium genus-specific PCR tests from ocular tissue of both eyes were negative. In

14 our view, these negative results do not exclude a direct mycobacterial effect on ocular disease, knowing the fact that our patient was

15 under long-term quadruple tuberculostatic therapy at the time of sampling and knowing the fact that the sensitivity of PCR results 
1

14 Funding: from aqueous or vitreous samples in ocular mycobacterial infections is low and is even lower from formalin-fixed paraffin-embedded tissues $(17,36)$. The relatively long postmortem interval might be another explanation for the negative results.(37) Immune reconstitution inflammatory syndrome due to antimicrobial therapy with overwhelming choroidal inflammation due to NTMs has to be discussed as the histopathology of our patient would also suit to ocular MAC reversal syndrome described among AIDS patients with antiretroviral therapy (18). However, our patient was HIV negative and not evidently immunosuppressed at the time of disease progression.

Our findings are based on a small case series and the observed OCT findings might not be pathognomonic for $M$. chimaera and rather represent choroidal infiltration independent of the causative agent. Nevertheless we think that NTM and especially $M$. chimaera infections should be in the differential among patients with uveitis and former cardiopulmonary bypass surgery.

In conclusion, disseminated $M$. chimaera infection after cardiothoracic surgery should be monitored by ocular multimodal imaging since choroidal manifestations are good indicators for systemic disease control.

\section{Funding:}


1 This study has been performed within the framework of the VASGRA (Vascular graft cohort study) supported by the Swiss National

2 Science Foundation (grant \# 32473B_163132). This study was supported by the University of Zurich (GVB, PMK). 


\section{References:}

3 1. Tortoli E, Rindi L, Garcia MJ, Chiaradonna P, Dei R, Garzelli C, et al. Proposal to elevate the genetic variant MAC-A,

4 included in the Mycobacterium avium complex, to species rank as Mycobacterium chimaera sp. nov. Int J Syst Evol Microbiol.

$5 \quad 2004 ; 54(\operatorname{Pt} 4): 1277-85$.

6 2. Wang A, Athan E, Pappas PA, Fowler VG, Jr., Olaison L, Pare C, et al. Contemporary clinical profile and outcome of

7 prosthetic valve endocarditis. JAMA. 2007;297(12):1354-61.

8 3. Covert TC, Rodgers MR, Reyes AL, Stelma GN, Jr. Occurrence of nontuberculous mycobacteria in environmental samples.

9 Appl Environ Microbiol. 1999;65(6):2492-6.

10 4. Achermann Y, Rossle M, Hoffmann M, Deggim V, Kuster S, Zimmermann DR, et al. Prosthetic valve endocarditis and

11 bloodstream infection due to Mycobacterium chimaera. J Clin Microbiol. 2013;51(6):1769-73.

12 5. Kohler P, Kuster SP, Bloemberg G, Schulthess B, Frank M, Tanner FC, et al. Healthcare-associated prosthetic heart valve,

13 aortic vascular graft, and disseminated Mycobacterium chimaera infections subsequent to open heart surgery. Eur Heart J.

$14 \quad 2015 ; 36(40): 2745-53$. 
16 Investigation of Mycobacterium chimaera infection associated with cardiopulmonary bypass. Public health England.

2 https://wwwgovuk/government/publications/health-protection-report-volume-9-2015/hpr-volume-9-issue-15-news-30-april)

$3 \quad 2015 ; 9(15)$

$4 \quad$ 7. Risk assessment on Mycobacterium chimaera infections associated with heater-cooler units. ECDC.

5 http://ecdceuropaeu/en/publications/Publications/mycobacterium-chimaera-infection-associated-with-heater-cooler-units-rapid-risk-

6 assessment-30-April-2015pdf 2015.

$7 \quad$ 8. Center of Disease control. Non tuberculous Mycobacterium (NTM) Infections and Heater Cooler Devices

8 Interim Practical Guidance: Updated October 27, 20152015 [Available from: http://www.cdc.gov/HAI/pdfs/outbreaks/CDC-Notice-

$9 \quad$ Heater-Cooler-Units-final-clean.pdf

10 9. Sax H, Bloemberg G, Hasse B, Sommerstein R, Kohler P, Achermann Y, et al. Prolonged Outbreak of Mycobacterium

11 chimaera Infection After Open-Chest Heart Surgery. Clin Infect Dis. 2015;61(1):67-75.

12 10. Haller S HC, Jacobshagen A, Hamouda O, Abu Sin M, Monnet DL, Plachouras D, Eckmanns T. Contamination during

13 production of heater-cooler units by Mycobacterium chimaera potential cause for invasive cardiovascular infections: results of an

14 outbreak investigation in Germany, April 2015 to February 2016. Euro Surveill. 2016;21(17).

15 11. Witmer MT, Parlitsis G, Patel S, Kiss S. Comparison of ultra-widefield fluorescein angiography with the Heidelberg

16 Spectralis $((\mathrm{R}))$ noncontact ultra-widefield module versus the Optos((R)) Optomap((R)). Clin Ophthalmol. 2013;7:389-94. 
12. Spaide RF, Koizumi H, Pozzoni MC. Enhanced depth imaging spectral-domain optical coherence tomography. Am J Ophthalmol. 2008;146(4):496-500.

13. Jabs DA, Nussenblatt RB, Rosenbaum JT, Standardization of Uveitis Nomenclature Working G. Standardization of uveitis nomenclature for reporting clinical data. Results of the First International Workshop. Am J Ophthalmol. 2005;140(3):509-16.

14. Peter-Getzlaff S, Luthy J, Voit A, Bloemberg GV, Bottger EC. Detection and identification of Mycobacterium spp. in clinical specimens by combining the Roche Cobas Amplicor Mycobacterium tuberculosis assay with Mycobacterium genus detection and nucleic acid sequencing. J Clin Microbiol. 2010;48(11):3943-8.

15. Deggim-Messmer V, Bloemberg GV, Ritter C, Voit A, Homke R, Keller PM, et al. Diagnostic Molecular Mycobacteriology in Regions With Low Tuberculosis Endemicity: Combining Real-time PCR Assays for Detection of Multiple Mycobacterial Pathogens

With Line Probe Assays for Identification of Resistance Mutations. EBioMedicine. 2016;9:228-37.

16. Griffith DE, Aksamit T, Brown-Elliott BA, Catanzaro A, Daley C, Gordin F, et al. An official ATS/IDSA statement: diagnosis, treatment, and prevention of nontuberculous mycobacterial diseases. Am J Respir Crit Care Med. 2007;175(4):367-416.

17. Marchetti G, Gori A, Catozzi L, Vago L, Nebuloni M, Rossi MC, et al. Evaluation of PCR in detection of Mycobacterium 4 tuberculosis from formalin-fixed, paraffin-embedded tissues: comparison of four amplification assays. J Clin Microbiol.

$1998 ; 36(6): 1512-7$. 
1 18. Girgis DO, Karp CL, Miller D. Ocular infections caused by non-tuberculous mycobacteria: update on epidemiology and 2 management. Clin Experiment Ophthalmol. 2012;40(5):467-75.

3 19. van Ingen J, de Zwaan R, Dekhuijzen R, Boeree M, van Soolingen D. Region of difference 1 in nontuberculous

4 Mycobacterium species adds a phylogenetic and taxonomical character. J Bacteriol. 2009;191(18):5865-7.

5 20. Sinawat S, Yospaiboon Y, Sinawat S. Bilateral endogenous endophthalmitis in disseminated NTM infection: a case report. J

$6 \quad$ Med Assoc Thai. 2011;94(5):632-6.

7 21. Lai LJ, Chen SN, Kuo YH, Ho JD, Ho CL. Presumed choroidal atypical tuberculosis superinfected with cytomegalovirus

8 retinitis in an acquired immunodeficiency syndrome patient: a case report. Jpn J Ophthalmol. 2002;46(4):463-8.

9 22. Grenzebach UH, Busse H, Totsch M, Dockhorn-Dworniczak B. Endophthalmitis induced by atypical mycobacterial infection.

10 Ger J Ophthalmol. 1996;5(4):202-6.

11 23. Tanemoto K, Ishikawa H, Kigasawa K, Obazawa H, Fusegawa H, Miyachi H, et al. [Detection of mycobacterial DNA with

12 polymerase chain reaction in eye discharge and gastric juices in a case of scleritis]. Nippon Ganka Gakkai Zasshi. 1997;101(1):97-

13101.

14 24. Moorthy RS, Valluri S, Rao NA. Nontuberculous mycobacterial ocular and adnexal infections. Surv Ophthalmol.

$15 \quad 2012 ; 57(3): 202-35$. 
1 25. Abu El-Asrar AM, Al-Mezaine HS. Anti-tuberculous therapy combined with systemic corticosteroids improves retinal

2 sensitivity in patients with active presumed tuberculous choroiditis. Int Ophthalmol. 2010;30(5):567-76.

3 26. Shakarchi FI. Ocular tuberculosis: current perspectives. Clin Ophthalmol. 2015;9:2223-7.

4 27. Akal A, Goncu T, Boyaci F, Sak Z, Yalcin F, Ozkan U, et al. Primary tubercular chorioretinitis. Ann Med Health Sci Res.

$5 \quad 2014 ; 4(6): 965-7$.

6 28. Invernizzi A, Mapelli C, Viola F, Cigada M, Cimino L, Ratiglia R, et al. Choroidal granulomas visualized by enhanced depth $7 \quad$ imaging optical coherence tomography. Retina. 2015;35(3):525-31.

8 29. Mrejen S, Spaide RF. Optical coherence tomography: imaging of the choroid and beyond. Surv Ophthalmol. 2013;58(5):3879429.

10 30. Schmitz-Valckenberg S, Holz FG, Bird AC, Spaide RF. Fundus autofluorescence imaging: review and perspectives. Retina. $11 \quad 2008 ; 28(3): 385-409$.

12 31. Rifkin LM, Munk MR, Baddar D, Goldstein DA. A new OCT finding in tuberculous serpiginous-like choroidopathy. Ocul

13 Immunol Inflamm. 2015;23(1):53-8.

14 32. Rudolf M, Vogt SD, Curcio CA, Huisingh C, McGwin G, Jr., Wagner A, et al. Histologic basis of variations in retinal pigment 15 epithelium autofluorescence in eyes with geographic atrophy. Ophthalmology. 2013;120(4):821-8. 
1 33. Alm A, Bill A. Ocular and optic nerve blood flow at normal and increased intraocular pressures in monkeys (Macaca irus): a

2 study with radioactively labelled microspheres including flow determinations in brain and some other tissues. Exp Eye Res.

$31973 ; 15(1): 15-29$.

4 34. Nickla DL, Wallman J. The multifunctional choroid. Prog Retin Eye Res. 2010;29(2):144-68.

5 35. Parver LM, Auker C, Carpenter DO. Choroidal blood flow as a heat dissipating mechanism in the macula. Am J Ophthalmol.

$6 \quad$ 1980;89(5):641-6.

7 36. Gupta V, Arora S, Gupta A, Ram J, Bambery P, Sehgal S. Management of presumed intraocular tuberculosis: possible role of

8 the polymerase chain reaction. Acta Ophthalmol Scand. 1998;76(6):679-82.

9 37. Bar W, Kratzer A, Machler M, Schmid W. Postmortem stability of DNA. Forensic Sci Int. 1988;39(1):59-70. 


\section{Legends}

$2 \quad$ Figure 1

3 Ultrawide-field photography of case 4 using Optomap scanning laser ophthalmoscope (A) and conventional fundus photography

4 (Zeiss Camera) (B) of the left eye demonstrating only three atrophic chorioretinal lesions (black and white arrows in A, white arrow in

5 B). The green line shows the location of the optical coherence tomography (OCT) scan. (C) Spectral-domain OCT of the chorioretinal

6 lesion (white arrow in A and B) shows marked choroidal atrophy.

$7 \quad$ Figure 2

8 A, Ultra wide-field photography using Optomap scanning laser ophthalmoscope of the right eye of a 61-year-old patient (case 5) with

9 progressive disseminated M. chimaera infection demonstrating a mild optic disc swelling and multifocal chorioretinal lesions. Similar

10 findings were observed in the fellow eye (not displayed) B, Wide-angle autofluorescence image shows multiple hyper- and

11 hypoautofluorescent lesions. C, Magnification of the area in the white box in A demonstrating yellow-whitish lesions (white arrows)

12 with well-defined borders which are hypoautofluorescent (D). E, F, Magnification of the area in the white box in A and B,

13 respectively. Fresh new active lesions with indistinct borders (arrows) were hyperautofluorescent (F) and could be observed in close

14 proximity to atrophic lesions which were hypoautofluorescent (F) (arrowhead). 


\section{Figure 3}

2 A, Ultra wide-field photography using Optomap scanning laser ophthalmoscope of the left eye of a patient (case 6) with progressive

3 disseminated M. chimaera infection. A, Wide-angle fundus photography showing multiple yellow-whitish chorioretinal lesions

4 disseminated M. chimaera infection. B, Magnification of the posterior pole (area contained in the white box in A) demonstrating

5 multiple, diffusely distributed, yellow-white chorioretinal lesions (white arrow, B). C and D, Early (C) and late (D) fluorescein

6 angiography images. Note the multiple hypo- and hyperfluorescent lesions present in the early phase, while late phase images

7 demonstrates hyperfluorescent lesions. $\mathbf{E}$ and $\mathbf{F}$, Indocyanine green angiography shows multiple hypofluorescent dots demarcated in

8 late phase $(\mathrm{F})$ that seem more numerous than the yellow-white spots seen in fundus photography (B).

\section{$9 \quad$ Figure 4}

10 Fundus photography of case 5 at baseline (A) and at five months follow-up visit (B) Note that the lesions present at baseline (white

11 long arrow in A) increased in size (white long arrow in B) and new lesions appeared (black arrowheads). Green lines show the

12 locations of the optical coherence tomography (OCT) scans. (C, D) OCT scans through choroidal lesions (short and long white arrow

13 in B) demonstrate clearly visible hyporeflective relatively homogenous round shaped lesions in the choroid (short and long white

14 arrow in $\mathrm{C}$ and $\mathrm{D}$ ) with elevation of the overlying retinal layers. Note that alterations of the integrity of the ellipsoid zone are visible

15 overlying the granuloma. D. Indocyanine green angiography shows multiple hypofluorescent lesions at baseline (E) and at five

16 months follow-up (F) that seem more numerous than the yellow-white spots seen in fundus photography (A, B). 
1 Figure 5

2 A, B, Ultrawide-field photography of case 5 at 9 month follow-up using Optomap scanning laser ophthalmoscope of the right (A) and

3 the left eye (B). Note that not only in the posterior pole but also in the periphery, a progression of the disease was observed. After

4 fixation in $4 \%$ formalin the right globe was sagitally (C), and the left globe horizontally (D) bisected. Note that the widespread

5 yellowish lesions correspond to granulomatous choroiditis in histology.

6 Figure 6

7 Histopathologic ocular findings of case five (A-F). Retina is artificially detached and absent from the micrographs. RPE: Retinal

8 pigmented epithelium; C: Choroid; S: Sclera. Choroidal inflammation consisting of granulomatous (A, He) and non-granulomatous,

9 patchy lympho-histiocytic infiltration $(\mathbf{B}, \mathrm{He})$. Granulomas without necrosis (A, inside circle) containing lymphocytes, histiocytes,

10 epithelioid and Langerhans giant cells (arrowhead). Lymphocytes mostly representing T-helper cells with immunoreactivity (red) for

11 CD4 (C, immunohistochemistry for CD4). Patchy uveitis with lymphocytes and CD68 positive histiocytes (D, immunohistochemistry

12 for CD68). Autopsy with granulomatous inflammation in the lung (E, inside circle), Langerhans giant cells (arrowhead) and acid

13 resistant rod within a lung granuloma (inside circle in F, Ziehl Neelsen). F. Higher magnification of the area inside circle demonstrates

14 acid resistant rod. Error! Bookmark not defined. 


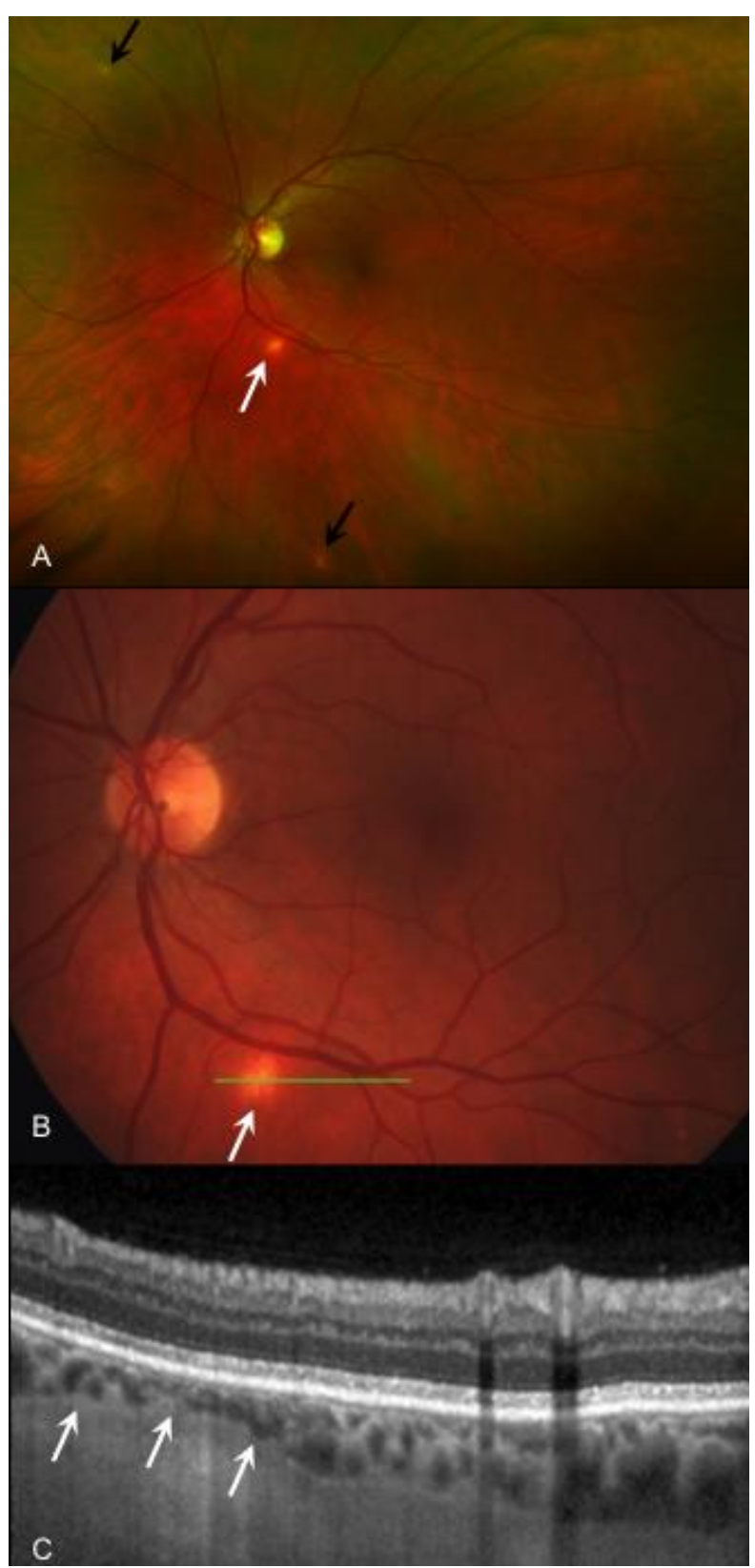




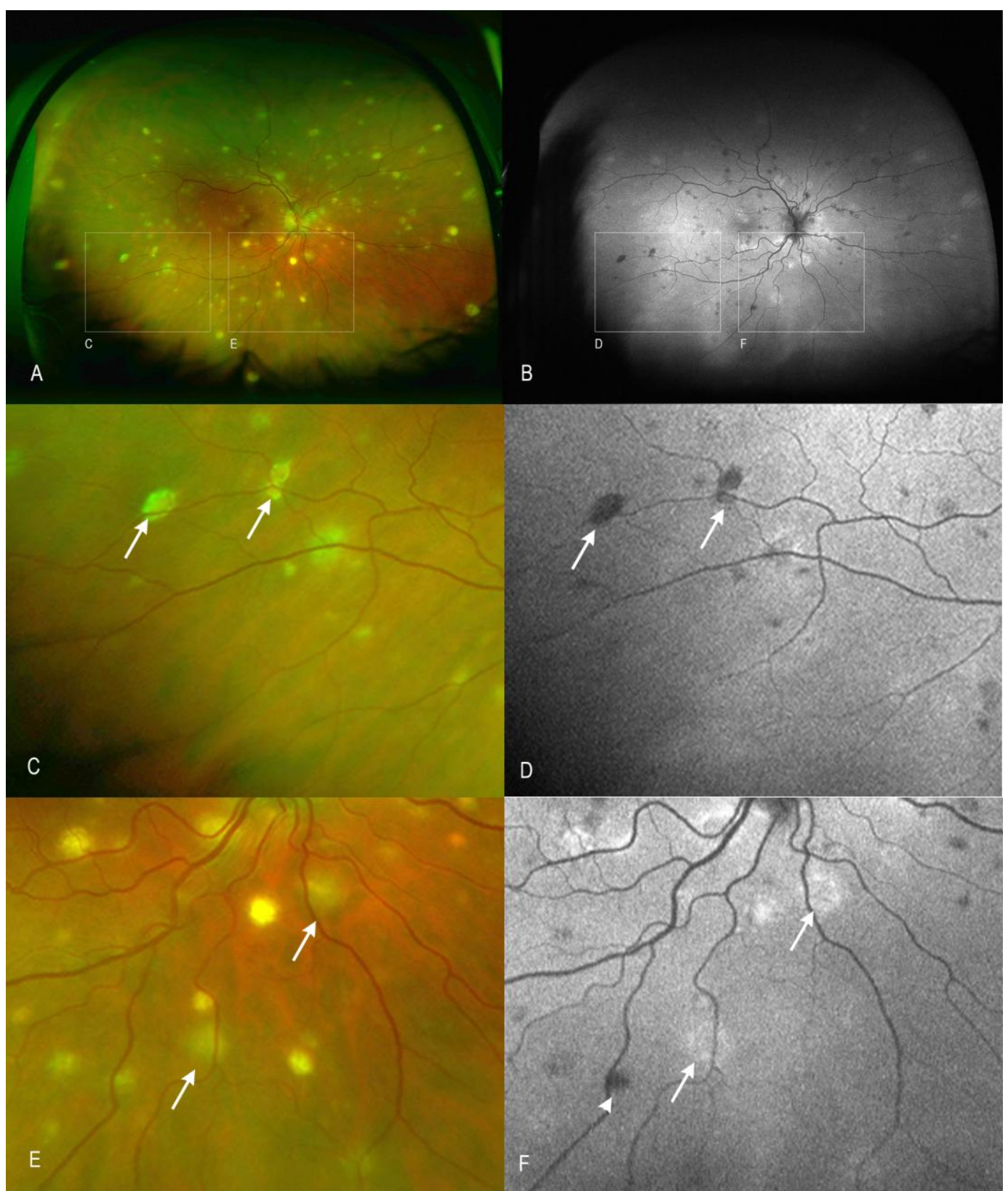




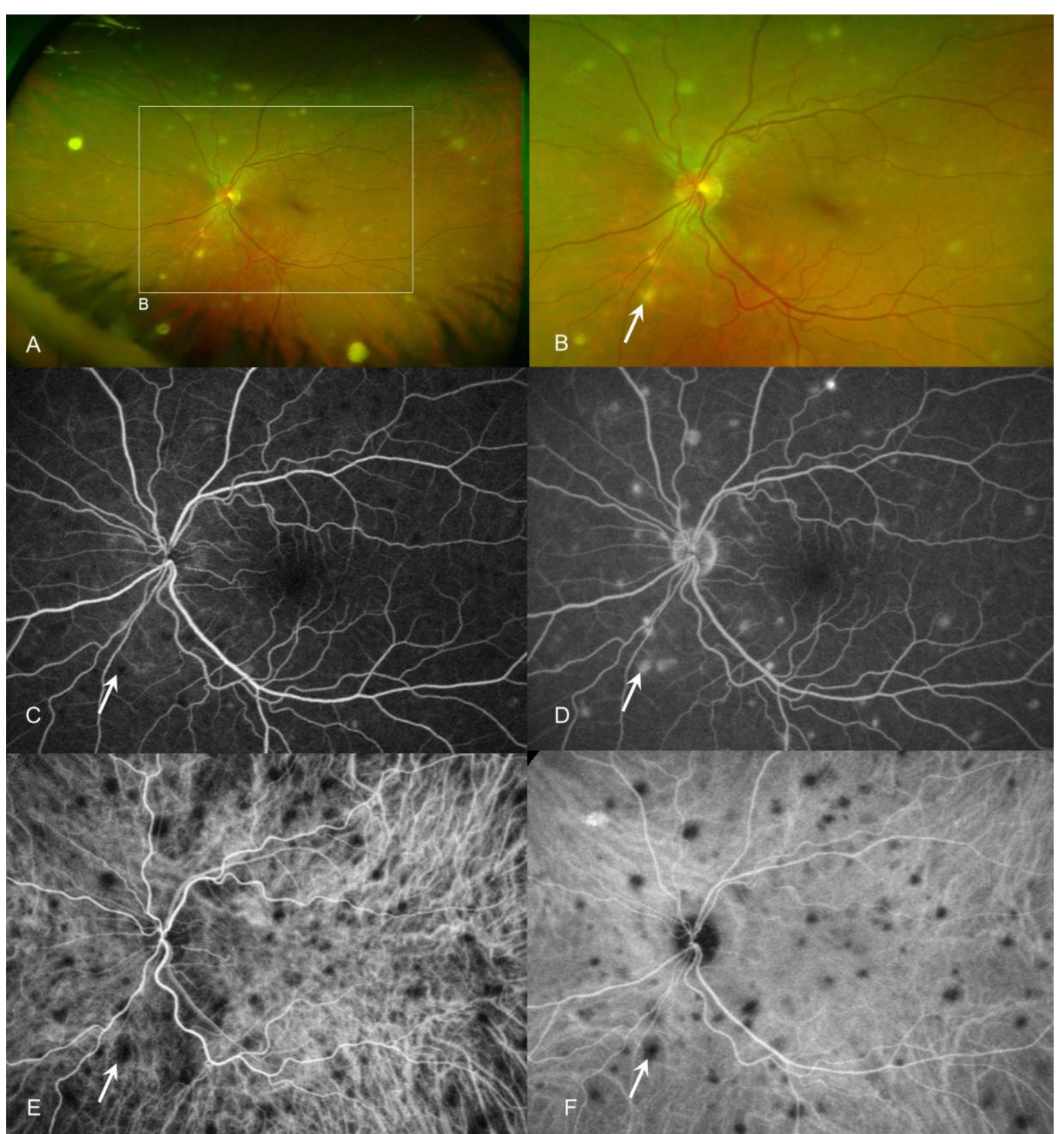




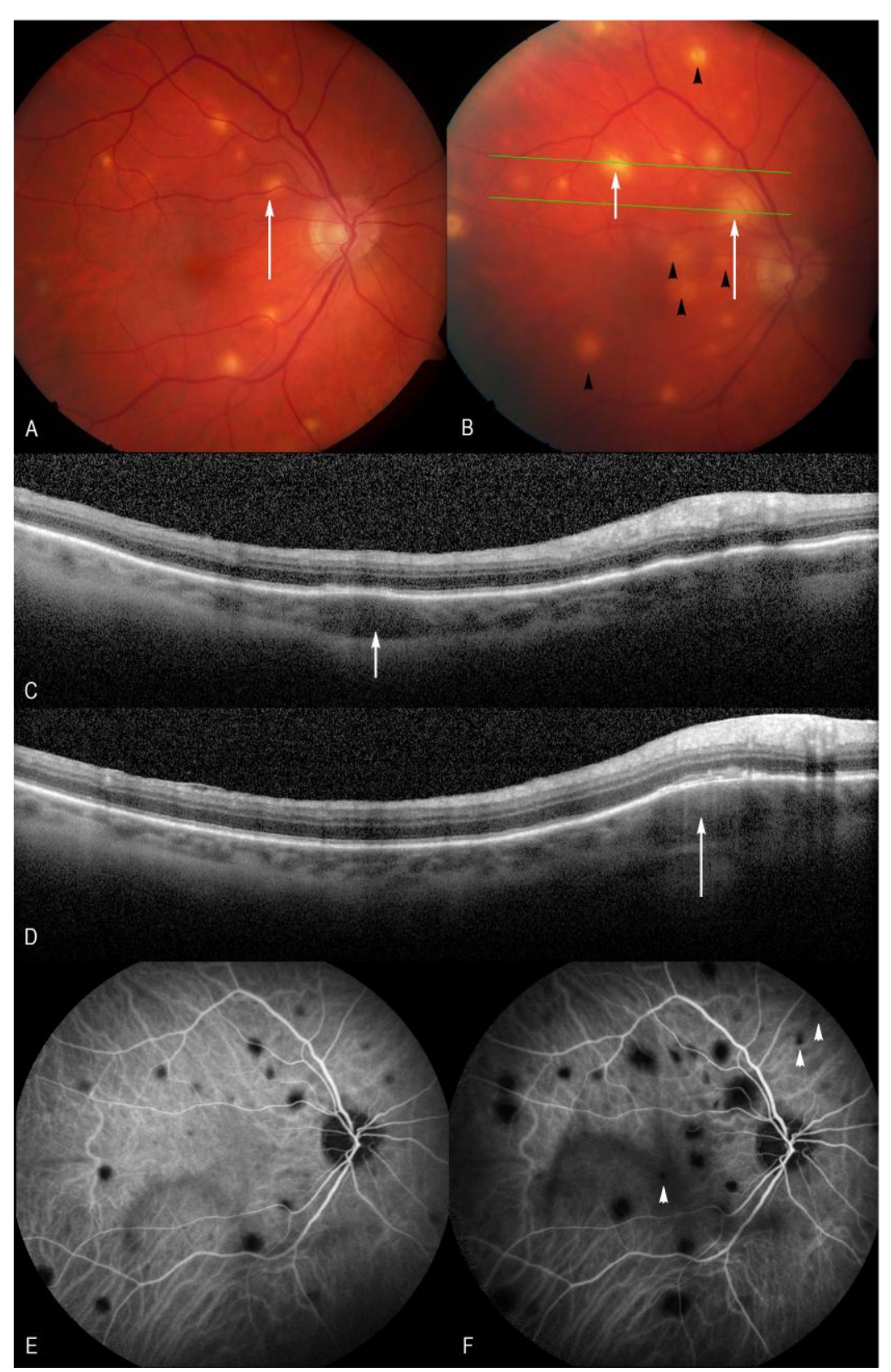




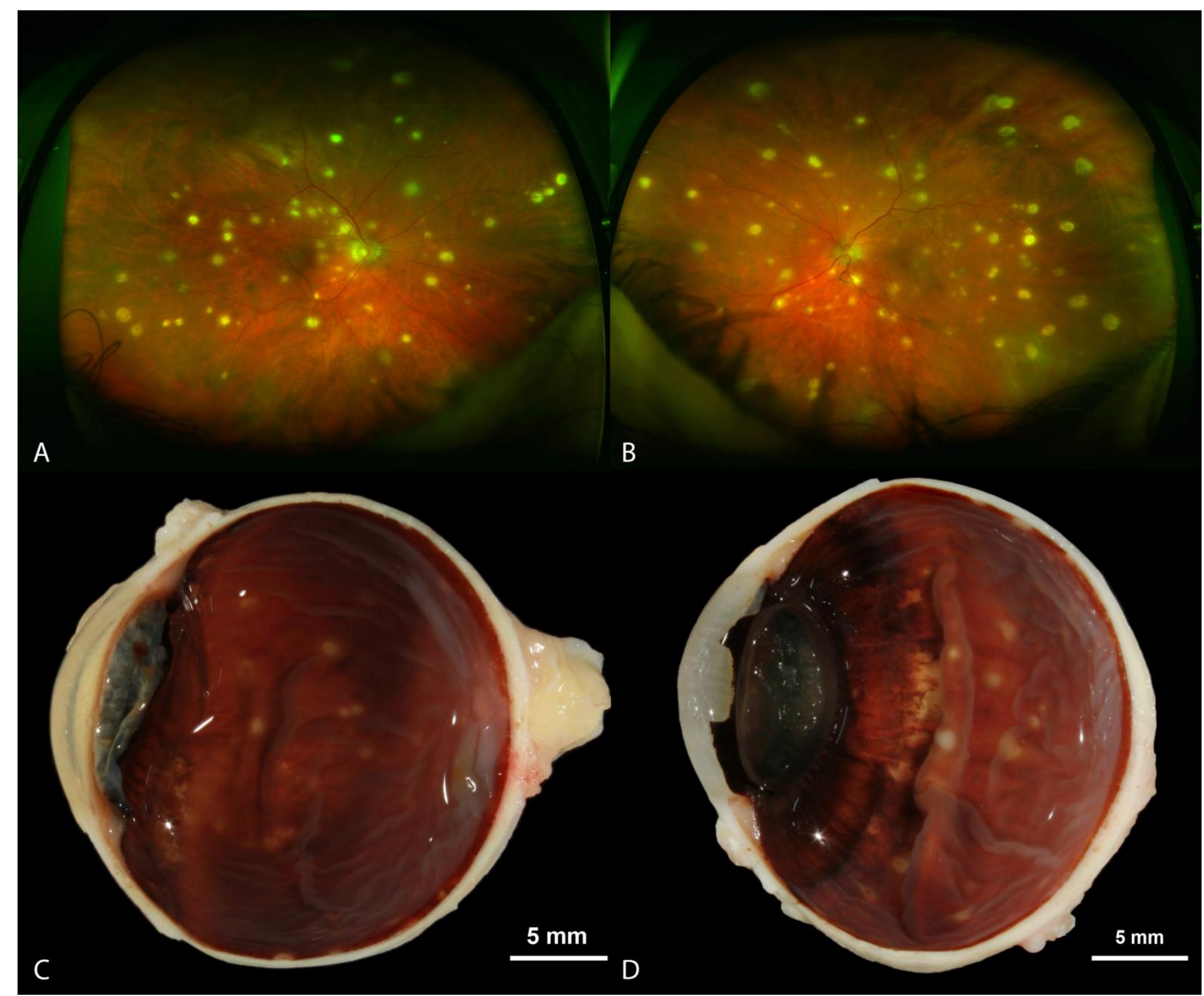




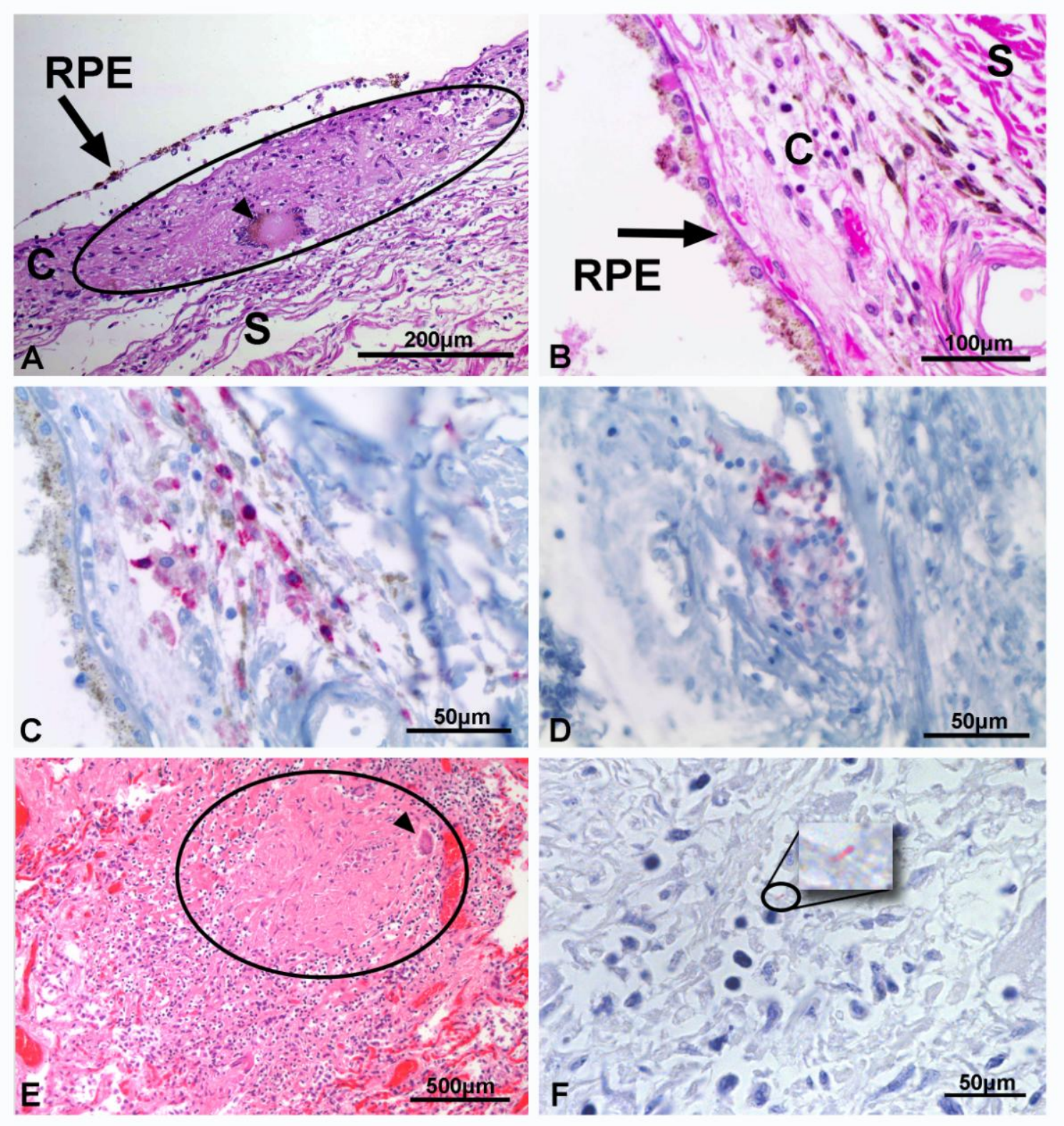


Table 1: Systemic and ocular characteristics of patients with disseminated M. chimaera

\begin{tabular}{|c|c|c|c|c|c|}
\hline & \multicolumn{5}{|c|}{ Cases } \\
\hline & 2 & 3 & 4 & 5 & 6 \\
\hline \multicolumn{6}{|l|}{ Characteristics } \\
\hline Sex & Male & Male & Male & Male & Male \\
\hline Age, years & 51 & 64 & 49 & 61 & 63 \\
\hline Immunosuppression & None & Methotrexate & $\begin{array}{l}\text { Azathioprine } \\
\text { Sulfasalazine }\end{array}$ & None & None \\
\hline \multicolumn{6}{|l|}{ Cardiac surgery } \\
\hline Type of surgery & $\begin{array}{l}\text { Composite graft } \\
\text { replacement }\end{array}$ & $\begin{array}{l}\text { Mitral valve } \\
\text { reconstruction }\end{array}$ & $\begin{array}{l}\text { Aortic valve } \\
\text { replacement }\end{array}$ & $\begin{array}{l}\text { Aortic root and arch } \\
\text { replacement }\end{array}$ & $\begin{array}{l}\text { Aortic root and arch } \\
\text { replacement }\end{array}$ \\
\hline $\begin{array}{l}\text { Date of index } \\
\text { cardiac surgery }\end{array}$ & 29.01 .2010 & 12.06 .2009 & 31.10 .2009 & 30.05 .2012 & 26.03 .2012 \\
\hline Infection & & & & & \\
\hline
\end{tabular}


Zweifel, SA et al. Mycobacterium chimaera Page 36

\begin{tabular}{|c|c|c|c|c|c|}
\hline $\begin{array}{l}\text { Time between index } \\
\text { surgery and } \\
\text { diagnosis }\end{array}$ & 1 year 4 months & 3 years 3 months & 3 years 5 months & 1 year 9 month & 1 year 10 month \\
\hline $\begin{array}{l}\text { Presenting } \\
\text { symptoms }\end{array}$ & $\begin{array}{l}\text { Vascular graft infection } \\
\text { Hepatitis } \\
\text { - } \\
\text { Pneumonitis } \\
\text { Splenomegaly } \\
\text { Pancytopenia }\end{array}$ & $\begin{array}{l}\text { Endocarditis with } \\
\text { cardiac insufficiency } \\
\text { Hepatitis } \\
\text { Renal Impairment } \\
\text { - } \\
\text { Splenomegaly } \\
\text { Pancytopenia } \\
\text { - }\end{array}$ & $\begin{array}{l}\text { Endocarditis with } \\
\text { cardiac insufficiency } \\
\text { Hepatitis } \\
\text { - } \\
\text { - } \\
\text { Splenomegaly } \\
\text { Pancytopenia } \\
\text { Arthritis }\end{array}$ & $\begin{array}{l}\text { Vascular graft infection } \\
\text { Hepatitis } \\
\text { Renal failure } \\
\text { - } \\
\text { Splenomegaly } \\
\text { Bizytopenia } \\
\text { Vertrebral } \\
\text { Osteomyelitis }\end{array}$ & $\begin{array}{l}\text { Vascular graft infection } \\
\text { Hepatitis } \\
\text { Renal impairment } \\
\text { - } \\
\text { Splenomegaly } \\
\text { Bizytopenia } \\
\text { - }\end{array}$ \\
\hline Ocular findings & $\begin{array}{l}\text { Endothelial precipitates } \\
\text { bilaterally } \\
\text { Mild anterior uveitis } \\
(0.5+\text { cells }) \text { and vitritis }\end{array}$ & $\begin{array}{l}\text { Few choroidal lesions } \\
\text { bilaterally } \\
\text { Mild anterior uveitis } \\
(0.5+\text { cells }) \text { and vitritis }\end{array}$ & $\begin{array}{l}\text { Few choroidal lesions } \\
\text { bilaterally }\end{array}$ & $\begin{array}{l}\text { Multifocal choroiditis } \\
\text { bilaterally }\end{array}$ & $\begin{array}{l}\text { Multifocal choroiditis } \\
\text { bilaterally } \\
\text { Left eye with anterior } \\
\text { uveitis (+cells) }\end{array}$ \\
\hline
\end{tabular}


Zweifel, SA et al. Mycobacterium chimaera Page 37

\begin{tabular}{|c|c|c|c|c|c|}
\hline & $\begin{array}{l}\text { (0.5+cells) bilaterally } \\
\text { Mild optic disc edema } \\
\text { bilaterally } \\
\text { Multifocal choroidal } \\
\text { lesions bilaterally }\end{array}$ & $(0.5+$ cells $)$ bilaterally & & & \\
\hline \multicolumn{6}{|l|}{ Treatment } \\
\hline $\begin{array}{l}\text { Tuberculostatic } \\
\text { treatment }\end{array}$ & $\begin{array}{l}\text { Clarithromycin } \\
\text { Ethambutol } \\
\text { Rifabutin }\end{array}$ & $\begin{array}{l}\text { Clarithromycin } \\
\text { Ethambutol } \\
\text { Rifabutin } \\
+ \\
\text { Moxifloxacin } \\
\text { Amikacin }\end{array}$ & $\begin{array}{l}\text { Clarithromycin } \\
\text { Ethambutol } \\
\text { Rifabutin } \\
+ \\
\text { Moxifloxacin } \\
\text { Amikacin }\end{array}$ & $\begin{array}{l}\text { Clarithromycin } \\
\text { Ethambutol } \\
\text { Rifabutin } \\
+ \\
\text { Moxifloxacin } \\
\text { Amikacin }\end{array}$ & $\begin{array}{l}\text { Clarithromycin } \\
\text { Ethambutol } \\
\text { Rifabutin } \\
+ \\
\text { Moxifloxcain } \\
\text { - }\end{array}$ \\
\hline Surgical treatment & - & $\begin{array}{l}\text { Redo: Excision of } \\
\text { Mitral ring } \\
\text { Replacement by new } \\
\text { Bio Mitral valve }\end{array}$ & $\begin{array}{l}\text { Redo: Aortic root } \\
\text { replacement }\end{array}$ & $\begin{array}{l}\text { Redo: Aortic root and } \\
\text { arch replacement }\end{array}$ & $\begin{array}{l}\text { Rethoracotomy } \\
\text { Debridement }\end{array}$ \\
\hline Outcome ocular & Progressive choroiditis & $\begin{array}{l}\text { Choroidal lesions stable } \\
\text { (inactive) }\end{array}$ & $\begin{array}{l}\text { Choroidal lesions stable } \\
\text { (inactive) }\end{array}$ & $\begin{array}{l}\text { Progressive choroiditis } \\
\text { Increase of choroidal }\end{array}$ & $\begin{array}{l}\text { Progressive choroiditis } \\
\text { Increase of choroidal }\end{array}$ \\
\hline
\end{tabular}


Zweifel, SA et al. Mycobacterium chimaera Page 38

\begin{tabular}{|c|c|c|c|c|c|}
\hline disease & & & & $\begin{array}{l}\text { lesions in size and } \\
\text { appearance of new } \\
\text { lesions }\end{array}$ & $\begin{array}{l}\text { lesions in size and } \\
\text { appearance of new } \\
\text { lesions }\end{array}$ \\
\hline Death & yes & no & no & yes & yes \\
\hline Reason of death & $\begin{array}{l}\text { Disseminated } M \text {. } \\
\text { chimaera infection } \\
\text { Splenic embolus and } \\
\text { rupture }\end{array}$ & - & - & $\begin{array}{l}\text { Disseminated } M \text {. } \\
\text { chimaera infection } \\
\text { Abdominal aortic } \\
\text { rupture }\end{array}$ & $\begin{array}{l}\text { Disseminated } M \text {. } \\
\text { chimaera infection } \\
\text { Cerebral vasculitis }\end{array}$ \\
\hline
\end{tabular}

1 Error! Bookmark not defined. 